\title{
Evaluation on Carrying Capacity of Economic, Resources and Environmental Based on the Improved Entropy Method
}

\author{
Luo Juan ${ }^{1, a}$, He Qingyan ${ }^{2, b}$ \\ 1 College of Mathematics and Computer Science, Wuhan Textile University, Wuhan, \\ 430073, China. \\ luojuan801128@163.com. \\ 2Jiaxing Foreign Language School, Jiaxing, 314000, China. \\ 66006914@qq.com
}

Keywords: Economy, Environment, Resources, Entropy Method

\begin{abstract}
The problem that how to coordinate the relationship between economic growth, environmental degradation and the reduction of resources is related to the sustainable development of human beings. In this paper, we calculate the economy, resources and environment index in the major cities of Hubei Province in 2014 by the improved entropy method. The results show that: for the major cities of Hubei province, there are relatively serious environmental pollution problems while economic development, indicating that economic growth mode is still high energy consumption, high resources. In the future, the government need to restrict industry of high consumption and high pollution, rational use of resources, and develop the water-saving and clean industry, focus on the industries of energy saving and environmental protection, as well as modern service industries such as tourism and logistics, so as to maintain the sustainable development of ecological economy.
\end{abstract}

\section{Introduction}

In recent years, though there is a rapid economic and social development in China, the consequent of shortage of resources, environmental pollution problems are becoming increasingly serious. [1] As an important area in the middle of our country, Hubei province is also facing the same economic environment and ecological problems. How to coordinate the relationship between economic growth, environmental degradation and the reduction of resources is related to the sustainable development of human beings. [2] In 1995, the view" the basic point of sustainable development is the coordination of economic and social development and resource environment, the core is the coordination of ecological and economic" was put forward in "national resource ,environment and economic development seminar".[3]

For this problem, the domestic and foreign scholars have carried on the related research through the establishment of index system. In the establishment of the index system for the evaluation of the research, in addition to the selection of indicators, an important content is the weight of the assignment. The method of determining the weight of the index mainly has the subjective assignment method and the objective assignment method. [4] The former is according to the evaluation of subjective attention degree to each index, such as analytic hierarchy process, the method of expert evaluation. The latter is to determine the index weight according to the data provided by the amount of information, such as the entropy method and factor analysis method. [5]The subjective assignment method is often highly subjective and may make the difference for different experts. The improved entropy method has good results when used in sustainable development and economic benefit evaluation. [6] In this paper, we calculate the economy, resources and environment index in the major cities of Hubei Province in 2014 by the improved entropy method, so as to propose reasonable suggestions for the future development strategy of the city economy in Hubei province. 


\section{Entropy method}

\section{A. Basic principles of entropy value method}

We get formation matrix $\left(x_{i j}\right)_{n \times m}$ through the original data, $\mathrm{n}$ is the number of index, $\mathrm{m}$ is the number of city. For an index $x_{j}$, if the gap of $x_{i j}$ is greater, the index in the comprehensive evaluation is very important; the less the vice. If values of an index are equal, then this index is ineffective in the comprehensive evaluation. In information theory, there is a function relationship: $H(x)=-\sum_{i=1}^{n} p\left(x_{i}\right) \ln p\left(x_{i}\right)$. The left $H(x)$ is information entropy, which is the disorder of the metric system; the right is information, which is the orderly degree of measurement system. For an index, the degree of discrete is the greater, $H(x)$ is less, then the amount of information provided by the indicator is greater and the weight is also greater; On the other hand, the degree of discrete is smaller, $H(x)$ is greater, the amount of information provided by the indicator is smaller and the weight is also smaller. So we can use information entropy to determine the index weight according to the discrete degree among indicators, which will provide a scientific basis for the ability of regional sustainable development evaluation.

B. Basic steps of entropy method

(i) Index quantification: we calculate proportion $p_{i j}$ of the jth index on the ith city.

$$
p_{i j}=\frac{x_{i j}}{\sum_{i=1}^{m} x_{i j}}
$$

(ii)We calculate entropy value $e_{j}$ of the jthindex: $e_{j}=-k \sum_{i=1}^{m} p_{i j} \ln p_{i j}$

$k>0$, Normally we set $k=1 / \ln m$, then $e_{j}=-(1 / \ln m) \sum_{i=1}^{m} p_{i j} \ln p_{i j}, 0 \leq e_{j} \leq 1$

(iii)We calculate coefficient of variation $g_{j}$ of the jthindex.If entropy value is smaller, the difference is greater, and this index is more important.

$$
g_{j}=1-e_{j}
$$

(iv)The weight of the jthindex $a_{j}: a_{j}=\mathrm{g}_{\mathrm{j}} / \sum_{j=1}^{n} \mathrm{~g}_{\mathrm{j}}$

(v)Comprehensive evaluation value of the ith year

$$
f_{i}=\sum_{j=1}^{n} a_{j} p_{i j}
$$

\section{Improved entropy method}

Because of using the logarithmic and entropy concept in the entropy value method, due to the negative can't directly involve in the calculation, so we need to change this kind of index data certainly. According to research, the entropy value method is more reasonable by standardized methods of data processing.

We use the following formula to standardize the index data:

$x_{i j}^{\prime}=\left(x_{i j}-x_{j}\right) / s_{j}$

There $x_{i j}^{\prime}$ is the standardization of parameter values, $x_{j}$ is mean for the jthindicator, $s_{j}$ is standard deviation for the jthindicator.

Using the following type to eliminate the negative effects by coordinate translation:

$z_{i j}=A+x_{i j}^{\prime}$

$Z_{i j}$ is the values after translation, $A$ is translational amplitude, then we use $Z_{i j}$ as $x_{\mathrm{ij}}$ to do data analysis through (1) - (5). 


\section{Evaluation on carrying capacity of economic resources and environmental in Hubei province}

\section{A. Index selection}

Because of the many factors that affect the economic and environment, we follow the scientific, hierarchical and operational principle, and choose representative, easy to quantify indicators from the economic, resources and environment. These indicators are in the following table 1.

Table 1 Index System of economic, resources and environment

\begin{tabular}{|c|c|c|}
\hline $\begin{array}{l}\text { First-grade } \\
\text { indexes }\end{array}$ & Second-grade indexes & Specific indexes \\
\hline \multirow[t]{5}{*}{ Economic } & \multirow{3}{*}{ Total amount } & Gross Domestic Production (billion yuan) \\
\hline & & Investment in Fixed Assets ( billion yuan) \\
\hline & & Growth rate of GDP (\%) \\
\hline & \multirow[t]{2}{*}{ Structure } & The proportion of industry output (\%) \\
\hline & & The proportion of tertiary industry (\%) \\
\hline \multirow[t]{5}{*}{ Resources } & \multirow[t]{2}{*}{ Water resources } & $\begin{array}{l}\text { Total Water Resources } \\
\text { ( million cubic meters ) }\end{array}$ \\
\hline & & $\begin{array}{l}\text { The per capita possession of water } \\
\text { resources (cubic meters) }\end{array}$ \\
\hline & \multirow[t]{2}{*}{ Land resources } & Land area (hectares) \\
\hline & & Cultivated area (hectares) \\
\hline & Forest resources & Forest cover area (hectares) \\
\hline \multirow[t]{3}{*}{ Environment } & \multirow{3}{*}{$\begin{array}{l}\text { Environmental } \\
\text { Science } \\
\text { Pollution }\end{array}$} & $\begin{array}{l}\text { Total volume of industrial waste water } \\
\text { discharged (10000 ton) }\end{array}$ \\
\hline & & $\begin{array}{l}\text { Total volume of industrial waste gas } \\
\text { discharged (10000 ton) }\end{array}$ \\
\hline & & $\begin{array}{l}\text { Total volume of industrial solid waste } \\
\text { discharged (10000 ton) }\end{array}$ \\
\hline
\end{tabular}

\section{B. Evaluation steps}

First, we make standardization of date according to the formula (6), and then coordinate translation according to (7). For the calculation, the index range is from- 2 to 2 .Therefore, the average amplitude is 2 ; and then we use $z_{i j}$ to calculate the weight value according to formula (1) (5).

\section{Results and conclusion}

In accordance with the above steps, we get the entropy value of the economy, resources and environment of Hubei Province in table 2. 
Table 2Entropy value of the economic, resources and environment

\begin{tabular}{|l|c|c|c|}
\hline Cities & $\begin{array}{l}\text { Economic } \\
\text { Factors }\end{array}$ & $\begin{array}{l}\text { Resources } \\
\text { Factors }\end{array}$ & $\begin{array}{l}\text { Environment } \\
\text { Factors }\end{array}$ \\
\hline Wuhan & 0.142 & 0.052 & 0.149 \\
\hline Huangshi & 0.070 & 0.041 & 0.112 \\
\hline Shiyan & 0.085 & 0.099 & 0.052 \\
\hline Yichang & 0.099 & 0.105 & 0.148 \\
\hline Xiangyang & 0.097 & 0.097 & 0.081 \\
\hline Ezhou & 0.063 & 0.028 & 0.064 \\
\hline Jingmen & 0.063 & 0.066 & 0.070 \\
\hline Xiaogan & 0.063 & 0.056 & 0.069 \\
\hline Jingzhou & 0.071 & 0.083 & 0.083 \\
\hline Huanggang & 0.067 & 0.094 & 0.051 \\
\hline Xianning & 0.072 & 0.074 & 0.054 \\
\hline Suizhou & 0.058 & 0.055 & 0.033 \\
\hline $\begin{array}{l}\text { Enshiacctonomous } \\
\text { prefecture }\end{array}$ & 0.051 & 0.149 & 0.034 \\
\hline
\end{tabular}

From the results in Table 2, it can be seen that as the capital city, Wuhan is the economic and trade center in Hubei province, the level of economic development is much higher than in other regions, but the environmental situation is not optimistic, environmental pollution problems is more severe and resources are not very rich compared to other regions. Economic development is extremely dependent on resources, especially non-renewable, so that pressure on resources and the environment is relatively serious. For Yichang and Xiangfan, although they are rich in natural resources, there is also serious environmental pollution, indicating that economic development is still somewhat high energy consumption, high resources. For economic development of other areas, there are also resources and environmental pressure problems. In the future, the government need to restrict industry of high consumption and high pollution, rational use of resources, and develop the water-saving and clean industry, focus on the industries of energy saving and environmental protection, as well as modern service industries such as tourism and logistics, so as to maintain the sustainable development of ecological economy.

\section{Acknowledgement}

In this paper, the research was sponsored by Research project of science and technology of Hubei Educational Committee in 2015 (Project No. Q20151609).

\section{References}

[1]QiaoJiajun.Application of Improve Entropy Method in Henan Sustainable Development Evaluation. Resources science. 2004.

[2] Han Shangfu, CaiBangcheng, Lu Genfa. Application of Improved Entropy Method in Evaluation Environmental Pressure Change of Industry of Jiangsu Province.Ecological Environment.2006.

[3]Wu Yuming, Zhang Yan.Analyzing Coupled Regional Economic Growth and Environment Conservation in China. Resources science. 2008.

[4]Zhu Li Evolutional analysis of social, Environmental and Economic development of Guangzhou by using entropy thory.Ecology and Environment.2008.

[5] Chen Zhaorong, Li Xunping, Wang Liang, Ye song. Evaluation on Regional Carrying Capacity 
of Resources and Environments Based on Entropy Model. Journal of Yibin University.2013.

[6] Yue Li, Gao Xincai ,ZhangQinzhi.Evaluation of regional circular economy development based on entropy method. Soft science.2011. 